\title{
FAMILIAL NON-AUTOIMMUNE HYPERTHYROIDISM IN FAMILY MEMBERS ACROSS FOUR GENERATIONS DUE TO A NOVEL DISEASE-CAUSING VARIANT IN THE THYROTROPIN RECEPTOR GENE
}

\author{
Malej A ${ }^{1}$, Avbelj Stefanija $\mathrm{M}^{2}$, Bratanič N², Trebušak Podkrajšek K ${ }^{2,3}$ \\ *Corresponding Author: Associate Professor Katarina Trebušak Podkrajšek, Ph.D., Institute of Bio- \\ chemistry and Molecular Genetics, Faculty of Medicine, University of Ljubljana, Slovenia. Tel: +386- \\ 1-543-7669. Fax: +386-1-543-7641. E-mail: katarina.trebusakpodkrajsek@mf.uni-lj.si
}

\begin{abstract}
Activating disease-causing variants in the thyrotropin-receptor $(T S H R)$ gene are associated with familial or sporadic congenital non-autoimmune hyperthyroidism. Familial non-autoimmune hyperthyroidism (FNAH) is a rare form of hyperthyroidism with 41 families reported so far in the TSHR gene mutation database. We present clinical and genetic features of 11 patients with FNAH across four generations of a Slovenian family. They all developed clinical features of hyperthyroidism but did not show characteristics of autoimmune hyperthyroidism. Members of the initially diagnosed generation were diagnosed as hyperthyrotic after they developed cardiac complications (rhythm disorders, thromboembolic events, cardiac insufficiency), while patients in the younger generations were diagnosed earlier, and consequently, early cardiovascular complications were less frequent. All patients had a novel heterozygous TSHR variant NP_000360.2: p.Met453Val (NM_000369.2: c.1357A $>$ G) predicted to be pathogenic. Therefore, besides expending the mutational spectrum of the activating TSHR variants in FNAH, our experience with this multi-generation family confirms the need for early diagnosis and appropriate treatment of FNAH.
\end{abstract}

Keywords: Activating variant; Familial non-autoimmune hyperthyroidism (FNAH); thyrotropin receptor; TSHR gene.

\footnotetext{
${ }^{1}$ Division of Internal Medicine, General Hospital Izola, Izola, Slovenia

${ }^{2}$ Deparment of Pediatric Endocrinology, Diabetes and Metabolism, University Medical Centre Ljubljana, University Children's Hospital, Ljubljana, Slovenia

${ }^{3}$ Institute of Biochemistry and Molecular Genetics, University of Ljubljana, Faculty of Medicine, Ljubljana, Slovenia
}

\section{INTRODUCTION}

Thyrotropin receptor (TSHR) is a G-protein coupled receptor that activates pathways enabling synthesis of the thyroid hormones, and proliferation of the thyrocytes [1]. Activating disease-causing variants in the thyrotropinreceptor (TSHR) gene are associated with non-autoimmune hyperthyroidism. In familial non-autoimmune hyperthyroidism (FNAH) activating variants are inherited in an autosomal dominant manner [2], while in sporadic congenital non-autoimmune hyperthyroidism (CNAH) they appear de novo [3]. Familial non-autoimmune hyperthyroidism is a rare disorder with 41 families reported so far in the TSHR gene mutation database [4]. The onset of the disease and clinical manifestations vary even between family members with the same disease-causing variant and might be influenced by the iodine intake and additional genetic factors [5]. Familial non-autoimmune hyperthyroidism is characterized by the positive family history of the nonautoimmune hyperthyroidism with autosomal dominant inheritance and can have variable onset and symptoms. Patients develop goiter, while clinical and laboratory signs of autoimmunity are not present [6]. Typically, patients with FNAH experience recurrence after withdrawal of the anti-thyroid treatment, non-ablative radioactive iodine (I-131) treatment, or partial thyroidectomy [7]. In addition to FNAH and CNAH, activating TSHR variants are associated with hot thyroid nodules as reviewed in recent report by Führer [8]. We present the clinical and genetic features of patients with FNAH across four generations of a Slovenian family due to a novel TSHR disease-causing variant.

\section{CASE REPORT}

The presented multi-generation family consists of relatives born between 1896 (subject I-1) and 2017 (sub- 
ject V-3) as illustrated in the family pedigree in Figure 1. Among the descendants, seven males and four females across four generations developed clinical features of hyperthyroidism but did not show characteristics of autoimmune hyperthyroidism [ophthalmopathy, dermopathy, TSH receptor antibodies (TSHAb), thyroglobulin (TG) antibodies; thyroid peroxidase (TPO) antibodies, hypoechoic pattern at an ultrasound, lymphocytic infiltration on histology]. All affected members shared some physical characteristics, they were tall, slim, had long thin fingers, aquiline nose, and staring eyes. Their clinical characteristics are summarized in Table 1.

Patients who were initially diagnosed in this family belonged to the second generation, while their father (subject I-1) was not clinically diagnosed but had similar physical characteristics. Patients II-1, II-4, II-5 and II-9 in the second generation were born between 1923 and 1940 and were diagnosed as hyperthyrotic after they had developed cardiac complications (rhythm disorders, thromboembolic events, cardiac insufficiency) when they were 40 to 60 years old (Table 1). Conservative treatment, namely antithyroid drugs and subtotal thyroidectomy, resulted in frequent relapses. They became long-term euthyrotic after they received I-131 administration, or total thyroidectomy and permanent substitutions of thyroid hormone. In this generation, clinical data were not available for subjects II-3, II-6, II-7, II-8, while brother II-2 was not affected. In the next generation born between 1951 and 1973, hyperthyroidism was diagnosed in four out of nine descendants (subjects III-2, III-5, III-6 and III-9). The diagnosis was made earlier between ages 17 and 40, mostly due to the awareness of the familial history. They were treated accordingly, and in contrast to the initially diagnosed generation, only subject III-5 developed cardiac complications after the diagnosis of hyperthyroidism. Clinical data was not available for subject III-4. In the fourth generation, born between 1980 and 2004, hyperthyroidism was confirmed in childhood before they were 10 years old. Pediatric treatment was conventional but no permanent remission was attained until I-131 administration. Children in the fifth generation were born between 2010 and 2017. So far, they are healthy.

Originally, genetic testing was carried out for subjects IV-2 and IV-3. We performed Sanger sequencing of the whole coding region and intron-exon junctions of the TSHR gene using the in-house designed primers (sequences available upon request), BigDye ${ }^{\circledR}$ Terminator v3.1 kit and ABI PRISM® 3500 Genetic Analyzer (Applied Biosystems, Waltham, MA, USA). Both initially analyzed subjects carried a heterozygous $T S H R$ variant changing methionine to valine at amino acid position 453 (NP_000360.2: p.Met453Val, NM_000369.2: c.1357A $>$ G) (Figure 2). The variant has not been reported in the TSHR mutation database [4], professional version of the Human Gene Mutation Database (HGMD) [9] database, ClinVar [10] or in general population in the Genome Aggregation Database (GnomAD) [11]. In silico models Sorting Intolerant from Tolerant SIFT [12], Polymorphism Phenotyping v2 (PolyPhen-2) [13], MutationTaster [14], and Combined Annotation Dependent Depletion (CADD) (score 25.2) [15], predicted it to be pathogenic. The variant was classified as likely pathogenic according to the American

Table 1. Summary of the clinical characteristics of the family members with hyperthyroidism. Additionally, all patients were tall and slim, they had long, thin fingers, aquiline nose, staring eyes and no exophthalmos.

\begin{tabular}{|c|c|c|c|c|c|c|c|c|c|}
\hline \multirow[t]{2}{*}{ Patient } & \multirow[t]{2}{*}{ Born } & \multirow[t]{2}{*}{ Died } & \multicolumn{2}{|c|}{ Age at Onset } & \multicolumn{2}{|c|}{ Antibodies (IU/mL) } & \multicolumn{3}{|c|}{ Treatment } \\
\hline & & & Нyp & $\mathrm{CVC}$ & AntiTG & AntiTPO & Antithyroid Drugs & Thyroidectomy & 131-Iodine \\
\hline $\mathrm{I}-1$ & 1896 & 1963 & NK & NK & NK & NK & NK & & \\
\hline II-1 & 1923 & 2008 & 42 & 60 & 55 & 37 & 3 years & {$[+]$} & \\
\hline II-4 & 1930 & 2004 & 45 & 46 & 48 & 54 & 9 years & & {$[+]$} \\
\hline II-5 & 1932 & 1998 & 51 & 50 & negative & negative & 7 years & & {$[+]$} \\
\hline II-9 & 1940 & 1991 & 40 & 40 & NK & NK & 2 years & & {$[+]$} \\
\hline III-2 & 1952 & & 40 & - & negative & negative & 6 years & & {$[+]$} \\
\hline III-5 & 1954 & 2007 & 24 & 26 & negative & negative & 3 years & & {$[+]$} \\
\hline III-6 & 1958 & & 23 & - & negative & negative & 4 years & {$[+]$} & {$[+]$} \\
\hline III-9 & 1973 & & 17 & - & negative & negative & 1 year & {$[+]$} & \\
\hline IV-2 & 1984 & & 10 & - & 80 & $>1000$ & 14 years & & \\
\hline IV-3 & 1988 & & 6 & - & negative & negative & 14 years & & {$[+]$} \\
\hline
\end{tabular}

Hyp: hyperthyroidism; CVC: cardiovascular complications; antiTG: thyroglobulin antibodies; antiTPO: thyroid peroxidase antibodies; NK: not known/analyzed. 


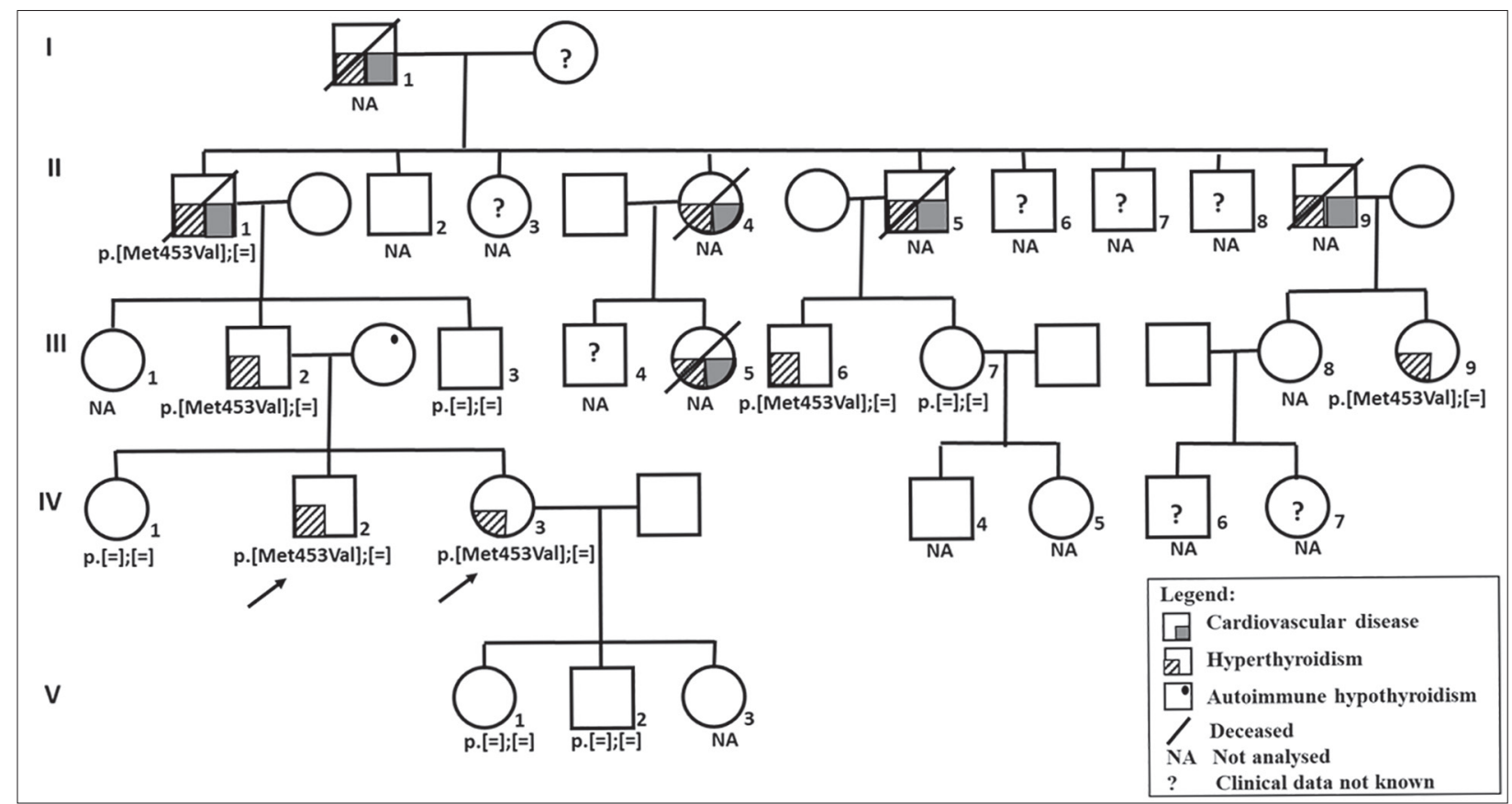

Figure 1. A family pedigree with clinical manifestations and observed TSHR gene disease-causing variant. The initially tested index patients are indicated by arrows. Variant in heterozygous state is marked as p.[Met453Val];[=], normal state is marked as p.[=];[=].

College of Medical Genetics and Genomics and the Association for Molecular Pathology (ACMG/AMP) 2015 guidelines [16] with the following grades: PM1 (located in mutational hot-spot), PM2 (absent from general population), PM5 (novel missense change at an amino acid residue where a different missense change determined to

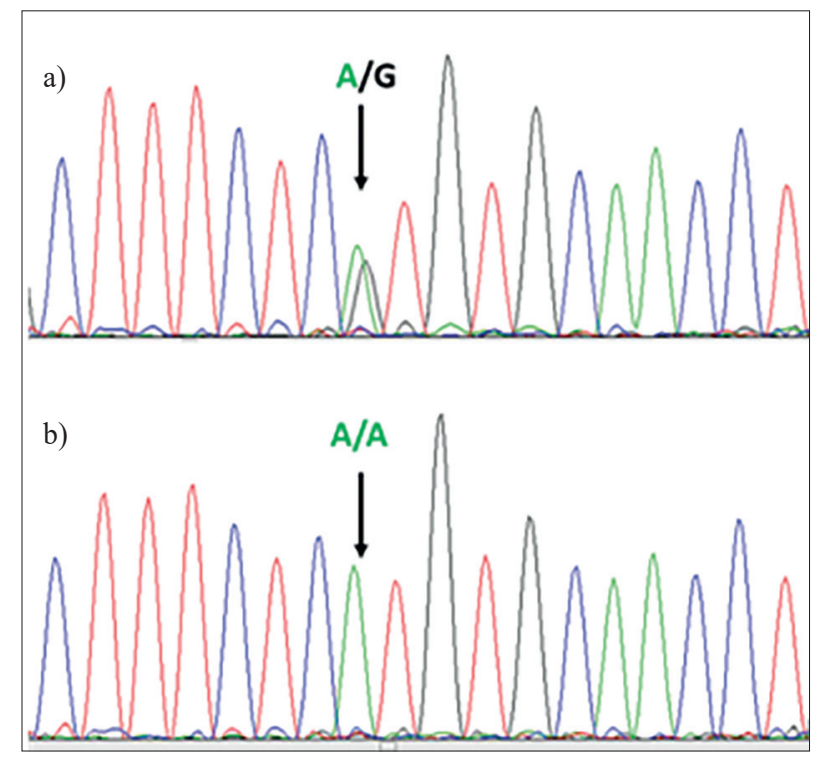

Figure 2. Electropherogram of the sequence from exon 10 of the TSHR gene with novel variant NP 000360.2: p.Met453Val (NM_000369.2: c.1357A $>$ G) in the hetero-zygous state (a) and normal sequence (b). be pathogenic has been seen), PP1 (co-segregation with the disease in multiple affected family members in a gene definitely known to cause the disease), PP3 (multiple lines of computational evidence supporting the deleterious effect), PP4 (patients phenotype and family history are highly specific for a disease with a single genetic etiology). Therefore, the novel p.Met453 Val variant was predicted to be causative for the FNAH, and this prediction was later confirmed by segregation analysis of the variant in other affected family members. Family members were examined only for the presence of the family $T S H R$ variant, and the analyses confirmed the presence of this variant in all tested family members who were affected. The analysis was not performed in all family members [marked as NA (not analyzed) in Figure 1].

\section{DISCUSSION}

We present the first multi-generation Slovenian family with FNAH due to a novel TSHR disease-causing variant. All affected subjects presented with low severity of hyperthyroid symptoms. Nevertheless, members of the second generation who were the initial patients in the family clinically diagnosed with non-autoimmune hyperthyroidism, had cardiac complications. For this generation, it is not clear exactly when hyperthyroidism started as they did not complain of specific hyperthyroid symptoms. Moreover, they all presented with a specific appearance, namely scrawny build, aquiline nose, staring 
eyes, and long, thin fingers. In later generations when hyperthyroidism was detected in childhood, family members typically had advanced stature compared to their chronological age. Subjects III-6 and III-9 underwent an early thyroidectomy at ages 25 and 18 years, respectively. Subject III-6 had thyroidectomy due to tracheal compression of the large goiter 3 years after ceasing to take methimazol. Subject III-9 had a thyroidectomy following the relapse of thyrotoxicosis 6 months after cessation of methimazol therapy.

As is typical for FNAH [5], the hyperthyroidism in affected family members could not be persistently controlled with antithyroid drugs and required a thyroidectemy and/or application of I-131. The exception was patient IV-2 with the TSHR family variant. When diagnosed, a small goiter without overt clinical signs of hyperthyroidism was observed. Elevated thyroid hormone levels and suppressed TSH were detected, while TSHR antibodies were determined several times, but were never detected. The treatment with antithyroid drugs was started several years later and he is currently euthyrotic. During followup, elevated TPO and TG antibody levels were detected. Nevertheless, the presence of the TPO or TG antibodies is common in the general population and was previously also reported in a limited number of FNAH patients [17]. In addition, the patient's mother is receiving therapy for autoimmune hypothyroidism (Figure 1).

The novel TSHR variant p.Met453Val detected in affected family members was predicted to be pathogenic, predominantly because it was not present in the general population. In silico tools predicted it to be pathogenic and it was located in the mutational hot-spot of the gene in the exon 10. Amino acid position 453 in the TSHR protein is highly conserved across species. Two different changes at the same amino acid position have so far been reported, namely, amino acid change of methionine to threonine (p.Met453Thr; c.1358T >C) $[18,19]$ and amino and acid change of methionine to arginine (p.Met453Arg; c.1358 $\mathrm{T}>\mathrm{G}$ ) [20]. Variant p.Met453Thr was reported in two Caucasian patients with CNAH that started in early childhood, one with severe neonatal hyperthyroidism [18] and the other with thyrotoxicosis [19]. Additionally, it was reported in a Thai family with three affected patients with different ages of onset [21]. Mutant TSHR carrying p.Met453 Thr had a 5-times activity increase in constitutive activity compared to the wild-type that was measured with basal cAMP activity and TSHR cell surface expression [22]. Additionally, the mutant TSHR carrying p.Met453Thr had enhanced constitutive internalization, but no recycling was observed [23]. Variant p.Met453Arg was reported in the Japanese family with non-autoimmune hyperthyroidism that was not severe and onset varying between childhood to adulthood [20]. The mutant TSHR carrying the p.Met 453Arg variant caused constitutive activation of the receptor [20]. These two disease-causing variants resulted in the change of the same amino acid as reported here and were functionally evaluated. Therefore, we can reliably claim the reported novel variant $p$.Met453Val to also be causative for non-autoimmune hypethyroidism.

Excess of thyroid hormones affects hemodynamic changes, and consequently, predisposes patients to heart failure as reviewed by Osuna et al. [24]. Furthermore, the mortality risk of patients with heart failure is significantly higher in patients with abnormal thyroid function [25]. Therefore, it is of utmost importance to diagnose and appropriately treat hyperthyroidism to prevent late cardiovascular complications in adults. This is significantly easier in inherited forms of hyperthyroidism in families where the familial disease-causing variant was identified. This was the case in the younger generations of the reported family where early cardiovascular complications were less frequent. Therefore, besides expanding the mutational spectrum of the activating TSHR variants in FNAH, our experience with this multi-generation family confirms the need for early diagnosis and appropriate treatment of FNAH.

Declaration of Interest. The authors report no conflicts of interest. The authors alone are responsible for the content and writing of this article.

Funding. This study was supported by funding from the Slovenian Research Agency [research core funding P3-0343 and P1-0170].

\section{REFERENCES}

1. Kero J, Ahmed K, Wettschureck N, Tunaru S, Wintermantel T, Greiner E, et al. Thyrocyte-specific Gq/ G11 deficiency impairs thyroid function and prevents goiter development. J Clin Invest. 2007; 117(9): 2399-2407.

2. Duprez L, Parma J, Van Sande J, Allgeier A, Leclère J, Schvartz C, et al. Germline mutations in the thyrotropin receptor gene cause non-autoimmune autosomal dominant hyperthyroidism. Nat Genet. 1994; 7(3): 396-401.

3. Kopp P, Van Sande J, Parma J, Duprez L, Gerber H, Joss E, et al. Congenital hyperthyroidism caused by a mutation in the thyrotropin-receptor gene. N Engl J Med. 1995; 332(3): 150-154.

4. Stephenson A, Lau L, Eszlinger M, Paschke R. The thyroid stimulating hormone receptor mutation database update. Thyroid. 2020; 30(6): 931-935. 
5. Paschke R, Niedziela M, Vaidya B, Persani L, Rapoport B, Leclere J. 2012 European thyroid association guidelines for the management of familial and persistent sporadic non-autoimmune hyperthyroidism caused by thyroid-stimulating hormone receptor germline mutations. Eur Thyroid J. 2012; 1(3): 142-147.

6. Ferraz C, Paschke R. Inheritable and sporadic non-autoimmune hyperthyroidism. Best Pract Res Clin Endocrinol Metab [Internet]. 2017; 31(2): 265-275. (Available at http://dx.doi.org/10.1016/j. beem.2017.04.005.)

7. Gozu HI, Lublinghoff J, Bircan R, Paschke R. Genetics and phenomics of inherited and sporadic nonautoimmune hyperthyroidism. Mol Cell Endocrinol. 2010; 322(1-2): 125-134.

8. Führer D. Constitutive TSH receptor activation as a hallmark of thyroid autonomy. Endocrine. 2020; 68(2): 274-278.

9. Human Gene Mutation Database (HGMD®) (http:// www.hgmd.cf.ac.uk/).

10. Landrum MJ, Chitipiralla S, Brown GR, Chen C, Gu $\mathrm{B}$, Hart J, et al. ClinVar: Improvements to accessing data. Nucleic Acids Res. 2020; 48(D1): D835-D844. doi: 10.1093/nar/gkz972.

11. Karczewski KJ, Francioli LC, Tiao G, Cummings BB, Alföldi J, Wang Q, et al. The mutational constraint spectrum quantified from variation in 141,456 humans. Nature. 2020; 581(7809): 434-443. doi: 10.1038/s41586- 020-2308-7. Epub 2020 May 27.

12. Ng PC, Henikoff S. SIFT: Predicting amino acid changes that affect protein function. Nucleic Acids Res. 2003; 31(13): 3812-3814.

13. Adzhubei IA, Schmidt S, Peshkin L, Ramensky VE, Gerasimova A, Bork P, et al. A method and server for predicting damaging missense mutations. Nat Methods. 2010; 7(4):248-249.

14. Schwarz JM, Cooper DN, Schuelke M, Seelow D. MutationTaster2: Mutation prediction for the deepsequencing age. Nat Methods. 2014; 11(4): 361-362.

15. Rentzsch P, Witten D, Cooper GM, Shendure J, Kircher M. CADD: Predicting the deleteriousness of variants throughout the human genome. Nucleic Acids Res. 2019; 47(D1): D886-D894.

16. Richards S, Aziz N, Bale S, Bick D, Das S, GastierFoster J, et al. Standards and guidelines for the interpretation of sequence variants: A joint consensus recommendation of the American College of Medical Genetics and Genomics and the Association for Molecular Pathology. Genet Med. 2015; 17(5): 405-424.
17. Fuhrer D, Warner J, Sequeira M, Paschke R, Gregory J, Ludgate M. Novel TSHR germline mutation (Met463 Val) masquerading as Graves' disease in a large Welsh kindred with hyperthyroidism. Thyroid. 2000; 10(12): 1035-1041.

18. De Roux N, Polak M, Couet J, Leger J, Czernichow $\mathrm{P}$, Milgrom E, et al. A neomutation of the thyroidstimulating hormone receptor in a severe neonatal hyper-thyroidism. J Clin Endocrinol Metab. 1996; 81(6): 2023-2026.

19. Lavard L, Sehested A, Jacobsen BB, Muller J, Perrild $\mathrm{H}$, Feldt-Rasmussen U, et al. Long-term follow-up of an infant with thyrotoxicosis due to germline mutation of the TSH receptor gene (Met453Thr). Horm Res. 1999; 51(1): 43-46.

20. Nakamura A, Morikawa S, Aoyagi H, Ishizu K, Tajima T. A Japanese family with nonautoimmune hyperthyroidism caused by a novel heterozygous thyrotropin receptor gene mutation. Pediatr Res. 2014; 75(6): 749-753.

21. Supornsilchai V, Sahakitrungruang T, Wongjitrat N, Wacharasindhu S, Suphapeetiporn K, Shotelersuk $\mathrm{V}$. Expanding clinical spectrum of non-autoimmune hyperthyroidism due to an activating germline mutation, p.M453 T, in the thyrotropin receptor gene. Clin Endocrinol (Oxf). 2009; 70(4): 623-628.

22. Lueblinghoff J, Mueller S, Sontheimer J, Paschke R. Lack of consistent association of thyrotropin receptor mutations in vitro activity with the clinical course of patients with sporadic non-autoimmune hyperthyroidism. J Endocrinol Invest. 2010; 33(4): 228-233.

23. Quellari M, Desroches A, Beau I, Beaudeux E, Misrahi $\mathrm{M}$. Role of cleavage and shedding in human thyrotropin receptor function and trafficking. Eur J Biochem. 2003; 270(17): 3486-3497.

24. Osuna PM, Udovcic M, Sharma MD. Hyperthyroidism and the heart. Methodist DeBakey Cardiovasc J. 2017; 13(2): 60-63.

25. Mitchell JE, Hellkamp AS, Mark DB, Anderson J, Johnson GW, Poole JE, et al. Thyroid function in heart failure and impact on mortality. JACC Hear Fail. 2013; 1(1): 48-55. 